Article

\title{
Screening and Evaluation of Xanthine Oxidase Inhibitors from Gnetum parvifolium in China
}

\author{
Xiaosheng Tang ${ }^{1,2}$, Ping Tang ${ }^{3}$, Lei Ma ${ }^{2, *}$ and Liangliang Liu ${ }^{4, *}$ (i) \\ 1 Hubei Key Laboratory of Edible Wild Plants Conservation and Utilization \& National Demonstration Center \\ for Experimental Biology Education \& College of Life Sciences, Hubei Normal University, \\ Huangshi 435002, China \\ 2 Zhengzhou Research Base, State Key Laboratory of Cotton Biology, Zhengzhou University, \\ Zhengzhou 450001, China \\ 3 School of Environmental Science and Engineering, Hubei Polytechnic University, Hubei Key Laboratory \\ of Mine Environmental Pollution Control and Remediation, Huangshi 435003, China \\ 4 Institute of Bast Fiber Crops, Chinese Academy of Agricultural Sciences, Changsha 410205, China \\ * Correspondence: malei@caas.cn (L.M.); liuliangliang@caas.cn (L.L.); \\ Tel.: +86-731-88998525 (L.M. \& L.L.)
}

Academic Editor: Seung Seo Lee

Received: 14 June 2019; Accepted: 22 July 2019; Published: 23 July 2019

\begin{abstract}
As a traditional natural medicine for treating many kinds of diseases, Gnetum parvifolium showed apparent inhibition on xanthine oxidase (XO). In this study, ultrafiltration combined with liquid chromatography-mass spectrometry (LC-MS) is used for the screening of XO inhibitors from Gnetum parvifolium. Their antioxidation, XO inhibition, and enzymic kinetic parameters are also determined. Finally, piceatannol (1), rhaponiticin (2), resveratrol (3), and isorhapontigenin (4) are screened out and identified as XO inhibitors from the extract of Gnetum parvifolium. Four inhibitors show better inhibition than allopurinol and good radical scavenging abilities. However, the antioxidant activities are weaker than ascorbic acid. The kinetic parameters illustrate the inhibition mode of $\mathrm{XO}$ by piceatannol is competitive type, while the inhibition modes for rhaponiticin, resveratrol and isorhapontigenin are uncompetitive types. In order to evaluate the difference among samples obtained in China, the amounts of four inhibitors and related activities in 20 samples are assessed and analyzed by partial least squares analysis. The results indicate piceatannol contribute the highest coefficients in three kinds of activities. Based on these findings, more comprehensive research on pharmaceutical and biochemical activities of these four XO inhibitors could be conducted in future.
\end{abstract}

Keywords: antioxidants; Gnetum parvifolium; inhibitor screening; ultrafiltration; xanthine oxidase

\section{Introduction}

Gnetum parvifolium is a green liana species belonging to the genus Gnetum. Its stem and root are usually used as natural medicines with acceptable therapeutic effects in treating rheumatic, aching limbs, acute respiratory infections, chronic bronchitis, and traumatic injuries in China [1,2]. Previous chemical research reported that flavonoids, stilbenoids, and alkaloids are several of the main components in Gnetum parvifolium [3]. Some findings showed the extract of Gnetum parvifolium could effectively inhibited the activity of xanthine oxidase $(\mathrm{XO})$ in vitro and reduce the level of blood uric acid in mice (Reference in Chinese). However, the report on particularly active components related to this activity is rare.

Plenty of active compounds exist in natural products. It makes natural products an invaluable source for exploring pharmaceutical and chemical active compounds [4]. However, various kinds of components make the finding, identification, and separation of active compounds complicated and 
time-consuming [5]. Among many novel screening methods, ultrafiltration combined with liquid chromatography-mass spectrometry (LC-MS) is an easy and efficient screening strategy based on specific protein-ligand interaction [6]. Ultrafiltration combined with LC-MS has become a useful tool for screening and identifying affinity ligands of proteins and enzymes from natural products [7-9]. During the ultrafiltration process, enzyme and bound ligands are trapped by membrane and further analyzed by LC-MS. Unnecessary isolation of inactive compounds is avoid in this screening method. Because this method focuses on target binding activity, it promotes the efficiency of analysis and simplifies the processes of experiment [10].

In this study, the inhibition of Gnetum parvifolium extract on XO in vitro is confirmed in our lab. $\mathrm{XO}$ inhibitors in Gnetum parvifolium extract are screened and identified using ultrafiltration combined with LC-MS. Four compounds are identified under the optimum screening conditions. Based on these results, detailed inhibition and antioxidant activities of these four compounds were conducted. In order to evaluate the difference among samples botained in China, 20 Gnetum parvifolium samples distributed in four provinces were collected and compared as well.

\section{Results and Discussion}

\subsection{Screening and Identification of XO Ligands}

Before the screening experiment, the inhibition of Gnetum parvifolium extract on XO was tested in order to guarantee if the further screening and evaluation of inhibitors would be worthwhile. As a result, the ethanol extract of Gnetum parvifolium showed apparent inhibition with $\mathrm{IC}_{50}$ value of $58.5 \mu \mathrm{g} / \mathrm{mL}$, which indicated that the Gnetum parvifolium extract contained XO inhibitors.

During ultrafiltration processes, ligands from extract bind to enzyme and form enzyme-ligand complexes in incubation. The complexes would remain during ultrafiltration by membrane. Meanwhile, the unbound compounds would pass through the membrane. Accordingly, in the chromatographic analysis, the peak areas of ligands would decrease after ultrafiltration [11]. Therefore, the decrease of peak area becomes an indicator for evaluation. After the optimization of chromatographic conditions, the representative chromatogram of Gnetum parvifolium extract and that of filtrate are shown in Figure 1. About four peaks could be considered as the ligands because the peak areas of them are decreased in filtrate. The validations of method are conducted by screening using positive and negative controls. The screening with denatured enzyme is also carried out. The results showed the screening is specific (data not shown).

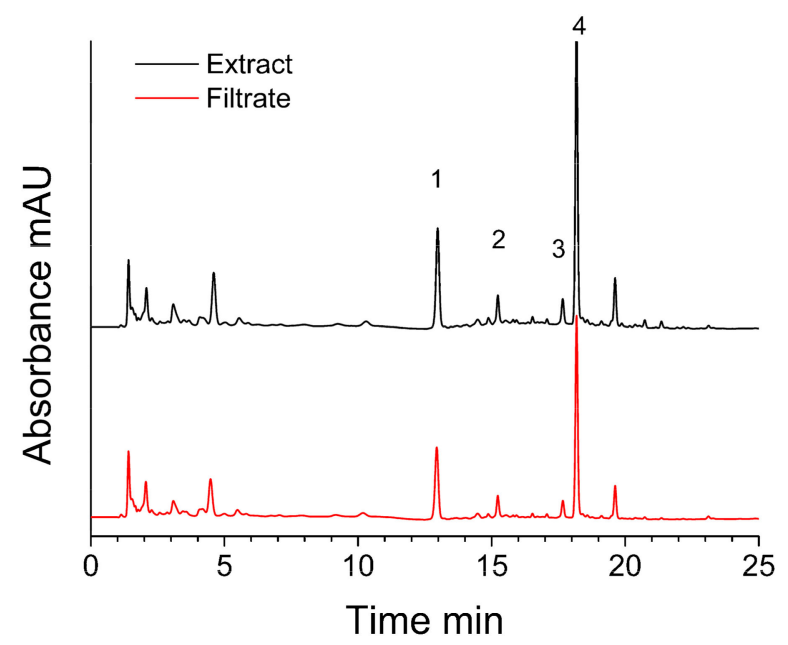

Figure 1. The chromatogram of Gnetum parvifolium extract (black) and filtrate after ultrafiltration (red).

High-performance liquid chromatography-mass spectrometry (HPLC-MS) analysis is then used to identify the marked four ligands. The structures of them are identified by analyzing and comparing 
their retention times, UV data, and MS data with those of authentic samples. The UV spectra of four compounds show wide absorbance at around $310 \mathrm{~nm}$. This is the typical spectra of stilbenoids, which are abundant in Gnetum parvifolium. In negative mode, the MS spectra of four compounds show the deprotonated molecular ions $\left([\mathrm{M}-\mathrm{H}]^{-}\right)$at 243, 419, 227, and 257, respectively. According to the previous reported information of stilbenoids, the retention times and MS spectra of authentic references are selected and compared with those of extract sample. Finally, they are identified as piceatannol (1) [12], rhaponiticin (2) [13], resveratrol (3) [14], and isorhapontigenin (4) [15] (Figure 2 and Table 1).

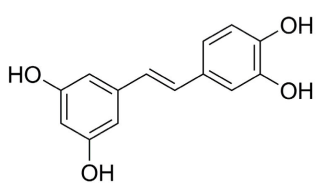

Piceatannol (1)

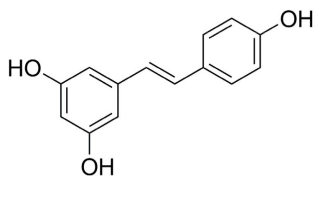

Resveratrol (3)

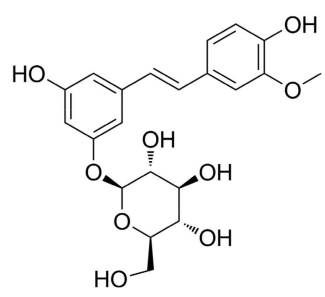

Rhaponiticin (2)

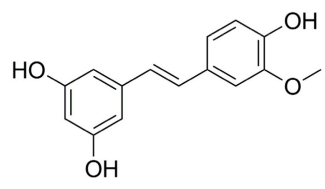

Isorhapontigenin (4)

Figure 2. The chemical structures of four inhibitors from Gnetum parvifolium extract.

Table 1. Identification of ligands in Gnetum parvifolium by liquid chromatography-mass spectrometry (LC-MS).

\begin{tabular}{ccccccc}
\hline Peak & Rt (min) & UV $(\mathbf{n m})$ & {$[\mathbf{M}-\mathbf{H}]^{-}$} & Mw & Formula & Identification \\
\hline 1 & 13.0 & 220,325 & 243 & 244 & $\mathrm{C}_{14} \mathrm{H}_{12} \mathrm{O}_{4}$ & Piceatannol \\
2 & 15.2 & 220,330 & 419 & 420 & $\mathrm{C}_{21} \mathrm{H}_{24} \mathrm{O}_{9}$ & Rhaponiticin \\
3 & 17.7 & 215,305 & 227 & 228 & $\mathrm{C}_{14} \mathrm{H}_{12} \mathrm{O}_{3}$ & Resveratrol \\
4 & 18.2 & 220,325 & 257 & 258 & $\mathrm{C}_{15} \mathrm{H}_{14} \mathrm{O}_{4}$ & Isorhapontigenin \\
\hline
\end{tabular}

\subsection{Inhibition and Kinetics Studies of Four Inhibitors}

The inhibition of four ligands on $\mathrm{XO}$ is tested in vitro. As a result, the four ligands show good inhibitions with $\mathrm{IC}_{50}$ values of $6.44,5.997,3.8,8$ and $46.75 \mu \mathrm{M}$ for piceatannol (1), rhaponiticin (2), resveratrol (3), and isorhapontigenin (4), respectively. Resveratrol shows the highest inhibitory activity, followed by rhaponiticin, piceatannol, and isorhapontigenin. As a commercially obtained inhibitor for $\mathrm{XO}$, allopurinol is used as a positive control with the $\mathrm{IC}_{50}$ value of $52.0 \mu \mathrm{M}$. Therefore, these four ligands could be considered as satisfying inhibitors for XO. Schmeda-Hirschmann et al. reported the methanol extract of Scirpus californicus inhibited XO, of which piceatannol was one of the targeted isolated components [16]. Gaballah et al. reported that resveratrol could markedly suppress XO and increase glutathione peroxidase activity [17]. However, the inhibitions on XO of rhaponiticin and isorhapontigenin were not previously reported.

In order to further exploring the inhibitory activities of four inhibitors, the inhibition type and inhibition kinetics constants were assayed. The activity was tested with different concentrations of substrates $(0.067,0.133$, and $0.267 \mathrm{mM})$ and different concentrations of inhibitors $(3.3,4.9$, and $6.6 \mu \mathrm{M}$ for piceatannol and resveratrol; 13, 20, and $26 \mu \mathrm{M}$ for rhaponiticin; 2.6, 3.9, and $5.3 \mu \mathrm{M}$ for isorhapontigenin). Figure 3 shows the Lineweaver-Burk plots for piceatannol, rhaponiticin, resveratrol, and isorhapontigenin and Table 2 shows some parameters. It could be seen through the plots that the mode of XO inhibition by piceatannol is competitive type and the modes of XO inhibition by rhaponiticin, resveratrol, and isorhapontigenin are uncompetitive type. The competitive inhibition means the Michaelis-Menten constant $\left(K_{m}\right)$ was increasing and the maximum reaction velocity $\left(V_{\max }\right)$ 
remained unchanged, which indicates the occupation by inhibitor prevents substrate from connecting to the active site of enzyme [18]. The uncompetitive inhibition means both $K_{m}$ and $V_{\max }$ are decreased, which indicates the inhibitor caused the inhibition by forming enzyme-substrate complex reversibly with weak interactions at a site other than the active site [19]. The $K_{i}$ values derived from secondary plots are $0.0027,0.085,0.052$, and $0.039 \mathrm{mM}$ for piceatannol, rhaponiticin, resveratrol, and isorhapontigenin, respectively. Smaller value of inhibition constant indicates stronger inhibition and the inhibitor-enzyme binding affinity exceeded the enzyme-substrate binding affinity [20].
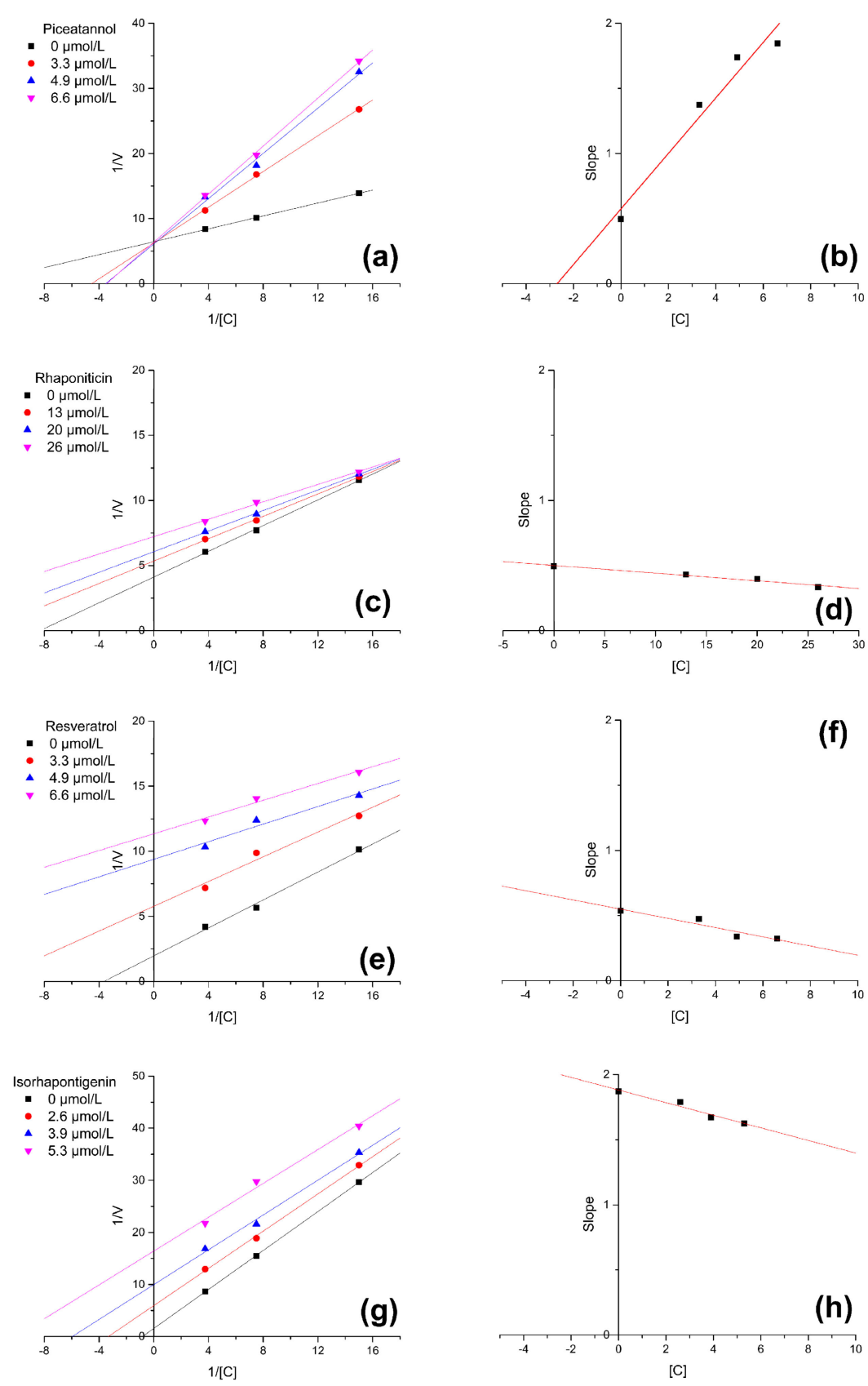

Figure 3. Lineweaver-Burk plots for inhibition of xanthine oxidase $(\mathrm{XO})$ by (a) piceatannol, (c) rhaponiticin, (e) resveratrol, and (g) isorhapontigenin. Secondary plots of slopes against concentrations of (b) piceatannol, (d) rhaponiticin, (f) resveratrol, and (h) isorhapontigenin to calculate $K_{i}$. 
Table 2. $\mathrm{EC}_{50}$ values, $\mathrm{IC}_{50}$ values, and kinetic parameters in enzymatic reactions of four inhibitors.

\begin{tabular}{|c|c|c|c|c|c|c|c|}
\hline Compounds & $\begin{array}{c}\mathrm{DPPH} \mathrm{EC}_{50} \\
(\mathrm{mM})\end{array}$ & $\begin{array}{c}\text { ABTS EC }_{50} \\
(\mathrm{mM})\end{array}$ & 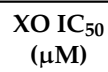 & {$[\mathrm{C}](\mu \mathrm{M})$} & $K_{m}(\mathrm{mM})$ & $\begin{array}{c}V_{\max } \\
(\mathrm{mmol} / \mathrm{min})\end{array}$ & $K_{i}(\mathrm{mM})$ \\
\hline \multirow[t]{4}{*}{ Piceatannol } & 0.04 & 0.01 & 6.44 & 0 & 0.077 & 0.155 & 0.0027 \\
\hline & & & & 3.3 & 0.220 & 0.160 & \\
\hline & & & & 4.9 & 0.287 & 0.164 & \\
\hline & & & & 6.6 & 0.290 & 0.157 & \\
\hline \multirow[t]{4}{*}{ Rhaponiticin } & 0.13 & 0.04 & 5.97 & 0 & 0.120 & 0.243 & 0.085 \\
\hline & & & & 13 & 0.081 & 0.187 & \\
\hline & & & & 20 & 0.065 & 0.165 & \\
\hline & & & & 26 & 0.046 & 0.139 & \\
\hline \multirow[t]{4}{*}{ Resveratrol } & 1.34 & 0.23 & 3.88 & 0 & 0.273 & 0.508 & 0.052 \\
\hline & & & & 3.3 & 0.082 & 0.173 & \\
\hline & & & & 4.9 & 0.036 & 0.106 & \\
\hline & & & & 6.6 & 0.028 & 0.088 & \\
\hline \multirow[t]{4}{*}{ Isorhapontigenin } & 1.45 & 0.30 & 46.75 & 0 & 0.450 & 0.281 & 0.039 \\
\hline & & & & 2.6 & 0.301 & 0.168 & \\
\hline & & & & 3.9 & 0.249 & 0.134 & \\
\hline & & & & 5.3 & 0.104 & 0.061 & \\
\hline
\end{tabular}

\subsection{Antioxidant Activity}

Antioxidant activities of four inhibitors were also determined by DPPH free radical scavenging and ABTS radical scavenging methods. The radical scavenging results are presented as $\mathrm{EC}_{50}$ values in Table 2. Ascorbic acid was used as the positive control with $\mathrm{IC}_{50}$ values of $0.02 \mathrm{mM}$ for DPPH and $0.02 \mathrm{mM}$ for ABTS. The rank in scavenging activities from the highest to the lowest is piceatannol, rhaponiticin, resveratrol, and isorhapontigenin for both DPPH and ABTS. The results show these four inhibitors have antioxidant activities as well. However, the scavenging activities of them are weaker than that of ascorbic acid. Lee et al. reported that piceatannol and resveratrol could scavenge DPPH free radical [21]. Yang et al. also reported the radical scavenging activities of piceatannol and isorhapontigenin [22]. However, the radical scavenging activities of rhaponiticin is first reported in this study.

\subsection{Comparison of Inhibitors among Different Gnetum Parvifolium Samples}

In order to calculate the contents of these four inhibitors in various Gnetum parvifolium distributed in China, 20 Gnetum parvifolium samples from four provinces were obtained and analyzed (detail information was shown in Table S1). The contents of four inhibitors, antioxidant activities, and XO inhibition are evaluated and shown in Table 3. Sample 13 showed the maximum activities for DPPH, ABTS, and XO, while sample 16 showed the minimum activities for DPPH and ABTS and the second minimum for $\mathrm{XO}$. The partial least squares analyses among four active compounds and activities were performed. As shown in Table 4, piceatannol contributes the highest coefficients for investigated three activities. Therefore, it could assume that the content of piceatannol in Gnetum parvifolium affects the investigating activities mostly.

\section{Materials and Methods}

\subsection{Chemicals and Materials}

Xanthine oxidase $(\mathrm{XO})$ freeze-dried powder was purchased from Yuanye Biotechnology Co. (Shanghai, China). Acetic acid and Acetonitrile in HPLC grade were purchased from Merck KGaA (Darmstadt, Germany). 1,1-Diphenyl-2-picrylhydrazyl (DPPH) and 2,2'-azinobis-(3-ethylbenzthiazoline- 6-sulfonic acid (ABTS) were bought from Merck KGaA (Darmstadt, Germany). Ultrapure water (18.2 $\mathrm{M} \Omega \mathrm{cm}$ resistivity) was obtained from an ELGA water purification system (ELGA Berkefeld, Veolia, Germany). Piceatannol (96.0\%) and resveratrol (99.0\%) were commercially acquired from Acros Organics (Fisher Scientific, PA, USA). Rhaponiticin (96.0\%) and Isorhapontigenin (96.0\%) were purchased from Yuanye Biotechnology Co. (Shanghai, China). All other chemicals were analytical grade and purchased from Sinopharm Chemical Reagent Co., Ltd. (Shanghai, 
China). Twenty Gnetum parvifolium samples were bought from pharmacies in Anhui, Guangxi, Hebei, and Guangdong province.

Table 3. The contents of four inhibitors, radical scavenging activities and XO inhibition of twenty Gnetum parvifolium samples. The concentration of each extract was unified at $2.0 \mathrm{mg} / \mathrm{mL}$.

\begin{tabular}{|c|c|c|c|c|c|c|c|}
\hline \multirow[t]{2}{*}{ No. } & \multicolumn{4}{|c|}{ Contents (mg/g) } & \multicolumn{3}{|c|}{ Bioactivity (Inhibition \%) } \\
\hline & Piceatannol & Rhaponiticin & Resveratrol & Isorhapontigenin & DPPH & ABTS & XO \\
\hline 1 & 1.7 & 60.1 & 37.4 & 184.0 & 33.5 & 69.2 & 36.4 \\
\hline 2 & 4.1 & 47.5 & 65.0 & 238.1 & 34.9 & 72.3 & 26.9 \\
\hline 3 & 5.7 & 51.2 & 71.6 & 169.8 & 40.2 & 76.8 & 83.8 \\
\hline 4 & 12.4 & 28.8 & 26.8 & 89.0 & 34.1 & 75.2 & 93.0 \\
\hline 5 & 0.8 & 36.0 & 40.2 & 201.1 & 42.2 & 76.7 & 66.2 \\
\hline 6 & 2.7 & 19.9 & 31.2 & 112.6 & 30.1 & 70.6 & 64.9 \\
\hline 7 & 2.5 & 12.0 & 32.5 & 36.6 & 355 & 83.3 & 93.7 \\
\hline 8 & 1.7 & 26.8 & 19.5 & 114.5 & 3.5 & 78.2 & 80.9 \\
\hline 9 & 3.4 & 14.0 & 22.2 & 61.7 & 3.0 & 68.7 & 55.7 \\
\hline 10 & 6.6 & 36.1 & 53.5 & 163.9 & 36.8 & 72.6 & 80.4 \\
\hline 11 & 10.6 & 78.4 & 62.7 & 272.1 & 36.8 & 70.7 & 40.3 \\
\hline 12 & 3.2 & 23.8 & 16.8 & 289.2 & 55.4 & 80.5 & 65.3 \\
\hline 13 & 16.6 & 56.1 & 39.5 & 153.9 & 77.8 & 96.0 & 96.2 \\
\hline 14 & 11.3 & 175.3 & 31.6 & 514.2 & 33.6 & 71.5 & 39.8 \\
\hline 15 & 9.8 & 65.2 & 57.6 & 271.7 & 50.6 & 80.2 & 77.1 \\
\hline 16 & 3.2 & 12.5 & 25.8 & 248.0 & 28.6 & 62.6 & 27.6 \\
\hline 17 & 5.4 & 41.0 & 52.5 & 304.8 & 37.4 & 78.7 & 89.4 \\
\hline 18 & 5.1 & 34.5 & 15.9 & 202.1 & 63.2 & 92.7 & 92.8 \\
\hline 19 & 1.1 & 18.1 & 20.3 & 164.3 & 46.2 & 90.7 & 47.7 \\
\hline 20 & 1.8 & 53.5 & 19.5 & 240.1 & 69.3 & 88.6 & 74.8 \\
\hline
\end{tabular}

Table 4. The parameters of partial least squares analysis of four active compounds and activities.

\begin{tabular}{cccc}
\hline \multirow{2}{*}{ Compounds } & \multicolumn{3}{c}{ Partial Least Squares Analysis } \\
\cline { 2 - 4 } & DPPH & ABTS & XO \\
\hline Piceatannol & 6.1743 & 2.8243 & 10.5320 \\
Rhaponiticin & -4.2698 & -1.2723 & -4.4226 \\
Resveratrol & -4.1071 & -2.6934 & -2.4919 \\
Isorhapontigenin & 3.4288 & -0.2928 & -7.6642 \\
\hline
\end{tabular}

\subsection{Extraction of Gnetum Parvifolium}

Gnetum parvifolium was extracted by microwave-assisted extraction method [23]. Twenty grams of samples were transferred into a conical flask containing $200 \mathrm{~mL}$ of $90 \%$ ethanol solution. The solution was extracted for $4 \mathrm{~min}$ in microwave oven at $60 \%$ power $(800 \mathrm{~W}, 2450 \mathrm{MHz}$, Galanz, G80W23CSL-A6, Guangdong, China). After extraction three times, the solvents were combined and evaporated with rotary evaporator under vacuum. Finally, $2.04 \mathrm{~g}$ of residues were dissolved in methanol or water and stored at $4{ }^{\circ} \mathrm{C}$ for further use.

\subsection{Inhibition Assay on $\mathrm{XO}$}

For inhibition test, $20 \mu \mathrm{L}$ of XO solution ( $1 \mathrm{mg} / \mathrm{mL}$ in buffers) and $1 \mathrm{~mL}$ of sample with different concentrations were mixed in a quartz cuvette. Then, $1 \mathrm{~mL}$ of $\mathrm{XO}(1 \mathrm{mg} / \mathrm{mL})$ was added to start reaction and the increase of absorbance at $295 \mathrm{~nm}$ in $100 \mathrm{~s}$ was recorded by an UV-Vis Spectrophotometer (UV2700, Shimadzu, Kyoto, Japan) [24]. Allopurinol was used as a positive control and water was used as a blank. The inhibitions of ethanol and methanol on XO were conducted, and there was no inhibition on $\mathrm{XO}$ for these two solvents. All experiments were performed in triplicate. The inhibition of XO was calculated by the following formula.

$$
\text { Inhibition } \%=\left(1-\Delta \mathrm{A}_{\mathrm{S}} / \Delta \mathrm{A}_{0}\right) \times 100
$$


where $\Delta \mathrm{A}_{\mathrm{s}}$ and $\Delta \mathrm{A}_{0}$ are the changes of absorbance for sample and blank, respectively. The inhibition of sample was expressed as the concentration of sample needed to inhibit $50 \%$ of enzymatic activity $\left(\mathrm{IC}_{50}\right)$.

\subsection{Screening of XO Inhibitors Using Ultrafiltration}

The screening was conducted using ultrafiltration according to our previous reports with some modifications [25]. Two-hundred microliters of XO solution $(1.0 \mathrm{mg} / \mathrm{mL})$ and $200 \mu \mathrm{L}$ of Gnetum parvifolium extract $(100 \mathrm{mg} / \mathrm{mL})$ were mixed in a tube and shaken at $25^{\circ} \mathrm{C}$ for $60 \mathrm{~min}$ with a thermostatic oscillator. After incubation, the mixture was transferred into a centrifugal filter (YM-30, the molecular weight cut off of $10 \mathrm{kDa}$ ) and centrifuged at $15492.5 \times \mathrm{g}$ for $20 \mathrm{~min}$ at $4{ }^{\circ} \mathrm{C}$ (Beckman Coulter Allegra 64R, Brea, CA, USA). The filtrate was collected for HPLC-MS analysis and the enzyme along with binding inhibitors were retained by membrane. Four-hundred microliters of buffer solution were added into the filter and the filter was centrifuged at the same conditions for the second time. Then, the filtrate was decanted and another $200 \mu \mathrm{L}$ of $80 \%$ methanol solution were added into the filter. The filter was centrifuged at $15492.5 \times \mathrm{g}$ for $20 \mathrm{~min}$ at $4{ }^{\circ} \mathrm{C}$ to elute binding inhibitors from enzymes and the filtrate named as eluent was collected for HPLC-MS. The control experiment was carried out in the same condition with denatured enzyme after high-temperature processing as a substitution.

\subsection{HPLC-MS Analysis}

The qualitative and quantitative analysis of screening was achieved by HPLC-MS analysis on an Agilent 1260 HPLC combined Agilent 6460 Triple Quadrupole LC-MS system (Agilent Technologies Inc., Santa Clara, CA, USA). The HPLC separation was completed using a $\mathrm{C}_{18}$ reverse phase column (Thermo Fisher Scientific, Hypersil GOLD, $100 \mathrm{~mm} \times 2.1 \mathrm{~mm}$ i.d., $3 \mu \mathrm{m}$, Waltham, MA, USA). A gradient elution program consisting of water and acetonitrile was used as follows: $0-5 \mathrm{~min}, 10 \%$ acetonitrile and 5-35 $\mathrm{min}, 10 \%-35 \%$ acetonitrile. The flow rate was set at $0.2 \mathrm{~mL} / \mathrm{min}$ and the column temperature was set at $25^{\circ} \mathrm{C}$. The chromatogram was recorded at $254 \mathrm{~nm}$. For mass spectrometry analysis, the Electron Spray Ionization (ESI) interface was used in negative ionization mode. The mass detection mode was set at full-scan mode from 100 to $1000 \mathrm{~m} / \mathrm{z}$.

\subsection{Antioxidation Tests}

The DPPH and ABTS radical scavenging tests were measured according to the reported method with some modifications [26,27]. For DPPH test, $0.5 \mathrm{~mL}$ of sample with different concentrations were mixed thoroughly with $2 \mathrm{~mL}$ of DPPH solution ( $0.1 \mathrm{mM}$ in methanol). The mixture was then kept in dark for $30 \mathrm{~min}$. Finally, the absorbance of solution was measured by an UV-Vis Spectrophotometer (UV2700, Shimadzu, Kyoto, Japan) at $517 \mathrm{~nm}$.

For ABTS test, ABTS solution ( $2 \mathrm{~mL}$ of ABTS stock solution $(0.01 \mathrm{M})$ added to $58 \mathrm{~mL}$ phosphate buffers, $\mathrm{pH}$ 7.0) was incubated for $12 \mathrm{~h}$ and diluted with methanol for use. Then, $0.5 \mathrm{~mL}$ of samples with different concentrations were mixed thoroughly with $2 \mathrm{~mL}$ of ABTS solution. The mixture was kept in dark for $30 \mathrm{~min}$, and the absorbance at $734 \mathrm{~nm}$ was measured by an UV-Vis Spectrophotometer. The same amount of water was used as control instead of sample. All experiments were performed in triplicate. The scavenging activity of DPPH and ABTS. radicals was calculated by the following formula:

$$
\text { Radical scavenging rate } \%=1-\mathrm{A}_{\mathrm{s}} / \mathrm{A}_{0} \times 100
$$

where $A_{0}$ was the absorbance of control and $A_{s}$ was the absorbance of sample. The radical scavenging activity of sample was expressed as the concentration of sample needed to scavenge $50 \%$ of DPPH or ABTS $\left(\mathrm{IC}_{50}\right)$.

\section{Conclusions}

In current study, ultrafiltration combined with HPLC-MS was used to screen XO inhibitors from Gnetum parvifolium. Piceatannol (1), rhaponiticin (2), resveratrol (3), and isorhapontigenin (4) 
were finally screened out and identified. They show good inhibitions and acceptable antioxidant activities compared with positive control. The inhibitions on $\mathrm{XO}$ of rhaponiticin and isorhapontigenin, as well as the radical scavenging activities of rhaponiticin, are first reported. The kinetic parameters exhibited the mode of $\mathrm{XO}$ inhibition by piceatannol is competitive type, while the inhibition modes for rhaponiticin, resveratrol, and isorhapontigenin are uncompetitive type. The amounts of four inhibitors and related activities in twenty samples obtained in China are assessed. The findings could contribute to a comprehensive understanding of the pharmaceutical potential use of Gnetum parvifolium as a natural source for $\mathrm{XO}$ inhibitors. These results also provide more phytochemical information for active constituents in Gnetum parvifolium.

Supplementary Materials: The following are available online. Table S1: The locations, batch numbers and species of twenty Gnetum parvifolium samples.

Author Contributions: Conceptualization, L.L.; Data curation, P.T.; Formal analysis, X.T.; Methodology, X.T. and L.M.; Writing—original draft, L.L. and L.M.

Funding: This work was supported by Open Foundation of Hubei Key Laboratory of Edible Wild Plants Conservation and Utilization (Grant No: EWPL201713).

Conflicts of Interest: The authors declare no conflict of interest.

\section{References}

1. Deng, N.; Chang, E.; Li, M.; Ji, J.; Yao, X.; Bartish, I.V.; Liu, J.; Ma, J.; Chen, L.; Jiang, Z.; et al. Transcriptome characterization of Gnetum parvifolium reveals candidate genes involved in important secondary metabolic pathways of flavonoids and stilbenoids. Front. Plant Sci. 2016, 7, 174. [CrossRef]

2. Deng, N.; Liu, C.; Chang, E.; Ji, J.; Yao, X.; Yue, J.; Bartish, I.V.; Chen, L.; Jiang, Z.; Shi, S. High temperature and UV-C treatments affect stilbenoid accumulation and related gene expression levels in Gnetum parvifolium. Electron. J. Biotechnol. 2017, 25, 43-49. [CrossRef]

3. Tian, L.W.; Lv, J.J.; Liu, Y.; Song, L.Y.; Hou, L.B.; Zhong, C.; Xie, Y. A new dimeric stilbene from the lianas of Gnetum parvifolium. Nat. Prod. Res. 2017, 31, 1495-1500. [CrossRef]

4. Li, L.; Kong, J.; Yao, C.H.; Liu, X.F.; Liu, J.H. Rapid identification of urokinase plasminogen activator inhibitors from Traditional Chinese Medicines based on ultrafiltration, LC-MS and in silico docking. J. Pharm. Biomed. Anal. 2019, 164, 241-248. [CrossRef]

5. Zuo, G.; Wang, Z.; Guillen Quispe, Y.N.; Hwang, S.H.; Kim, H.Y.; Kang, B.G.; Lim, S.S. Target guided isolation of potential tyrosinase inhibitors from Otholobium pubescens (Poir.) J.W. Grimes by ultrafiltration, high-speed countercurrent chromatography and preparative HPLC. Ind. Crop. Prod. 2019, 134, 195-205. [CrossRef]

6. Guo, Y.; Fu, R.; Qian, Y.; Zhou, Z.; Liu, H.; Qi, J.; Zhang, B.; Yu, B. Comprehensive screening and identification of natural inducible nitric oxide synthase inhibitors from Radix Ophiopogonis by off-line multi-hyphenated analyses. J. Chromatogr. A 2019, 1592, 55-63. [CrossRef]

7. Fu, Y.; Luo, J.; Qin, J.; Yang, M. Screening techniques for the identification of bioactive compounds in natural products. J. Pharm. Biomed. Anal. 2019, 168, 189-200. [CrossRef]

8. Hou, W.; Li, S.; Li, S.; Shi, D.; Liu, C. Screening and isolation of cyclooxygenase-2 inhibitors from Trifolium pratense L. via ultrafiltration, enzyme-immobilized magnetic beads, semi-preparative high-performance liquid chromatography and high-speed counter-current chromatography. J. Sep. Sci. 2019, 42, 1133-1143. [CrossRef]

9. Liu, M.; Liu, Q.; Chen, M.; Huang, X.; Chen, X. Large-scale separation of acetylcholinesterase inhibitors from Zanthoxylum nitidum by $\mathrm{pH}$-zone-refining counter-current chromatography target-guided by ultrafiltration high-performance liquid chromatography with ultraviolet and mass spectrometry screening. J. Sep. Sci. 2019, 42, 1194-1201. [CrossRef]

10. Xiao, S.; Yu, R.; Ai, N.; Fan, X. Rapid screening natural-origin lipase inhibitors from hypolipidemic decoctions by ultrafiltration combined with liquid chromatography-mass spectrometry. J. Pharm. Biomed. Anal. 2015, 104, 67-74. [CrossRef]

11. Chen, M.; Liu, L.; Chen, X. Preparative isolation and analysis of alcohol dehydrogenase inhibitors from Glycyrrhiza uralensis root using ultrafiltration combined with high-performance liquid chromatography and high-speed countercurrent chromatography. J. Sep. Sci. 2014, 37, 1546-1551. [CrossRef] 
12. Ślusarczyk, S.; Senol Deniz, F.S.; Woźniak, D.; Pecio, Ł.; Pérez-Sánchez, H.; Cerón-Carrasco, J.P.; Stochmal, A.; den-Haan Alonso, H.; Matkowski, A.; Orhan, I.E. Selective in vitro and in silico cholinesterase inhibitory activity of isoflavones and stilbenes from Belamcandae chinensis rhizoma. Phytochem. Lett. 2019, 30, 261-272. [CrossRef]

13. Qiu, Y.K.; Chen, F.F.; Zhang, L.L.; Yan, X.; Chen, L.; Fang, M.J.; Wu, Z. Two-dimensional preparative liquid chromatography system for preparative separation of minor amount components from complicated natural products. Anal. Chim. Acta 2014, 820, 176-186. [CrossRef]

14. Fernández-Marín, M.I.; Guerrero, R.F.; García-Parrilla, M.C.; Puertas, B.; Richard, T.; Rodriguez-Werner, M.A.; Winterhalter, P.; Monti, J.-P.; Cantos-Villar, E. Isorhapontigenin: A novel bioactive stilbene from wine grapes. Food Chem. 2012, 135, 1353-1359. [CrossRef]

15. Gabaston, J.; Richard, T.; Biais, B.; Waffo-Teguo, P.; Pedrot, E.; Jourdes, M.; Corio-Costet, M.F.; Mérillon, J.M. Stilbenes from common spruce (Picea abies) bark as natural antifungal agent against downy mildew (Plasmopara viticola). Ind. Crop. Prod. 2017, 103, 267-273. [CrossRef]

16. Schmeda-Hirschmann, G.; Gutiérrez, M.I.; Loyola, J.I.; Zúñiga, J. Biological activity and xanthine oxidase inhibitors from Scirpus californicus (C. A. Mey.) Steud. Phytother. Res. 1996, 10, 683-685. [CrossRef]

17. Gaballah, H.H.; Zakaria, S.S.; Elbatsh, M.M.; Tahoon, N.M. Modulatory effects of resveratrol on endoplasmic reticulum stress-associated apoptosis and oxido-inflammatory markers in a rat model of rotenone-induced Parkinson's disease. Chem-Biol. Interact. 2016, 251, 10-16. [CrossRef]

18. De Araújo, M.E.M.B.; Franco, Y.E.M.; Alberto, T.G.; Messias, M.C.F.; Leme, C.W.; Sawaya, A.C.H.F.; Carvalho, P.d.O. Kinetic study on the inhibition of xanthine oxidase by acylated derivatives of flavonoids synthesised enzymatically. J. Enzym. Inhib. Med. Chem. 2017, 32, 978-985. [CrossRef]

19. Akin, S.; Ayaloglu, H.; Gultekin, E.; Colak, A.; Bekircan, O.; Akatin, M.Y. Synthesis of 1,2,4-triazole-5-on derivatives and determination of carbonic anhydrase II isoenzyme inhibition effects. Bioorg. Chem. 2019, 83, 170-179. [CrossRef]

20. Majouli, K.; Besbes Hlila, M.; Hamdi, A.; Flamini, G.; Ben Jannet, H.; Kenani, A. Antioxidant activity and $\alpha$-glucosidase inhibition by essential oils from Hertia cheirifolia (L.). Ind. Crop. Prod. 2016, 82, $23-28$. [CrossRef]

21. Lee, S.K.; Mbwambo, Z.H.; Chung, H.; Luyengi, L.; Gamez, E.J.; Mehta, R.G.; Kinghorn, A.D.; Pezzuto, J.M. Evaluation of the antioxidant potential of natural products. Comb. Chem. High Throughput Screen. 1998, 1, 35-46. [PubMed]

22. Lu, Y.; Wang, A.; Shi, P.; Zhang, H.; Li, Z. Quantum chemical study on the antioxidation mechanism of piceatannol and isorhapontigenin toward hydroxyl and hydroperoxyl radicals. PloS ONE 2015, 10, e0133259. [CrossRef] [PubMed]

23. Liu, L.; Yuan, M.; Huang, S.; Li, J.; Li, D.; Zhao, L. Analysis of xanthine oxidase inhibitors from Clerodendranthus spicatus with xanthine oxidase immobilized silica coated $\mathrm{Fe}_{3} \mathrm{O}_{4}$ nanoparticles. Appl. Sci. 2018, 8, 158. [CrossRef]

24. Liu, L.L.; Shi, S.Y.; Zhao, H.D.; Yu, J.G.; Jiang, X.Y.; Chen, X.Q. Selective fishing and analysis of xanthine oxidase binders from two Fabaceae species by coupling enzyme functionalized core-shell magnetic nanoparticles with HPLC-MS. J. Chromatogr. B 2014, 945, 163-170. [CrossRef] [PubMed]

25. Cen, Y.; Xiao, A.P.; Chen, X.Q.; Liu, L.L. Isolation of -amylase inhibitors from Kadsura longipedunculata using a high-speed counter-current chromatography target guided by centrifugal ultrafiltration with LC-MS. Molecules 2016, 21, 1190. [CrossRef] [PubMed] 
26. Sridhar, K.; Charles, A.L. In vitro antioxidant activity of Kyoho grape extracts in DPPH and ABTS assays: Estimation methods for EC50 using advanced statistical programs. Food Chem. 2019, 275, 41-49. [CrossRef] [PubMed]

27. Fan, H.; Sun, L.; Yang, L.; Zhou, J.; Yin, P.; Li, K.; Xue, Q.; Li, X.; Liu, Y. Assessment of the bioactive phenolic composition of Acer truncatum seed coat as a byproduct of seed oil. Ind. Crop. Prod. 2018, 118, 11-19. [CrossRef]

Sample Availability: Samples are not available.

(C) 2019 by the authors. Licensee MDPI, Basel, Switzerland. This article is an open access article distributed under the terms and conditions of the Creative Commons Attribution (CC BY) license (http://creativecommons.org/licenses/by/4.0/). 